\title{
Disparen contra Imperio. Una aproximación crítica a la obra de Hardt y Negri \\ María Clara Musante
}

María Clara Musante es Licenciada en Comunicación

Social y Becaria CONICET.

E-mail: cahiamusante@hotmail.com

\section{resumen}

En los años ochenta, el campo de las ciencias sociales se vio sacudido por la crisis de los paradigmas tradicionales experimentada como corolario de la derrota sufrida por los movimientos de izquierda, de gran protagonismo en la etapa anterior. La fractura de los "grandes relatos" y el promocionado fin de la historia abonaron el surgimiento de una nueva corriente de pensamiento llamada posmodernismo. Sin embargo, en el año 2000, un "acontecimiento" singular genera un cimbronazo en el ámbito intelectual, académico y hasta mediático. Un libro de filosofía, que rápidamente se convierte en un boom editorial, se presenta como "la reescritura del Manifiesto Comunista" del siglo XXI, la "primera gran síntesis teórica del nuevo milenio": el libro Imperio, de Negri y Hardt. El trabajo que aquí presentamos retoma algunas problemáticas de la polémica generada a partir de dicha obra, en un intento de contribución a un debate todavía latente.

\section{summary}

In the eighties, the field of social sciences was shaken by the crisis of the traditional paradigms experienced as corollary of the defeat suffered by the leftwing movements, of great protagonism in the previous stage. The fracture of the "big narratives" and the promoted End of History fertilized the emergence of a new current of thought called postmodernism.

Nevertheless, in the year 2000, a singular "event" generates a shaken in the intellectual, academic and even in the mediatic field. A book of philosophy, which rapidly turns into a publishing boom, that presents itself as "the rewriting of the Communist Manifest" of the XXI century, the "first great theoretical synthesis of the new millennium": the book Empire, by Negri and Hardt. The text that we present here recaptures some problems of the polemic generated from the mentioned work, in an attempt of contribution to a still latent debate

\section{palabras clave}

Imperio / imperialismo / multitud / clase social

\section{keywords}

Empire / imperialism / crowd / social class 


\section{Introducción}

En los años ochenta, el campo de las ciencias sociales se vio sacudido por la crisis de los paradigmas tradicionales experimentada como corolario de la derrota sufrida por los movimientos de izquierda, de gran protagonismo en la etapa anterior. La fractura de los "grandes relatos" y el promocionado fin de la historia abonaron el surgimiento de una nueva corriente de pensamiento llamada posmodernismo.

Más allá de la variedad de autores, teorías, perspectivas, puntos de vistas y formas de denominar una "nueva" época - posmodernidad, modernidad líquida o tardomodernidad- que pondría en crisis las formas tradicionales de pensar la sociedad y el Estado, lo que estaba en cuestionamiento era principalmente uno de los "relatos" fundantes de la ciencia política: el marxismo.

Sin embargo, en el año 2000, un "acontecimiento" singular genera un cimbronazo en el ámbito intelectual, académico y hasta mediático. Un libro de filosofía, que rápidamente se convierte en un boom editorial, se presenta como "la rees-critura del Manifiesto Comunista" del siglo XXI, la "primera gran síntesis teórica del nuevo milenio".

De una manera novedosa, pero no por ello totalmente original, los autores realizaban una articulación de perspectivas teóricas que hasta ese momento aparecían como antagónicas e irreconciliables. La tradición marxista, particularmente estructuralista (rescatando la figura de Spinosa), el posestructuralismo de Foucault y Deleuze y el discurso posmodernista se imbricaban para analizar de una manera totalizante (quizás una las mayores virtudes del libro, cuando el concepto de totalidad era fuertemente cuestionado) las nuevas condiciones del capitalismo "desterritorializado".

La aparición de Imperio, escrito por el filósofo italiano Antonio Negri y el profesor de literatura Michael Hardt, generó posiciones fuertes, con acérrimos defensores y jueces despiadados que expresaron el amor y el odio con la misma intensidad. En esto reside precisamente el valor del libro. Su publicación permitió la apertura de un debate en el ámbito de la teoría que hasta entonces parecía hallarse cautiva del pensamiento "débil" y la convivencia pacifica de las ideas.

Con este trabajo pretendemos adentrarnos en ese debate inconcluso y aproximarnos a algunos de los temas más controvertidos y provocadores planteados en sus páginas. En particular, intentaremos reflexionar sobre la noción de "Imperio" como superador del concepto de imperialismo, retomando el núcleo de las polémicas que se generaron a su alrededor.

En este sentido, nuestro "ensayo" estará dividido en tres momentos. En primer lugar, realizaremos una descripción sobre los aspectos principales que definen la constitución del nuevo sistema de poder mundial, destacando su singularidad y diferencia con la fase anterior y evaluando las condiciones por las cuales se afirma que este término es el indicado para comprender la dinámica propia del capitalismo posmodernista.

En segundo lugar, se busca abordar las tesis centrales del libro a través de la exposición de ejemplos concretos que den cuenta de las críticas formuladas por sus detractores. 
Por último, la propuesta es ensayar algunas "conclusiones" a modo de interrogantes sobre las problemáticas actuales de las ciencias sociales a partir de algunas situaciones de la política internacional que permiten poner en tensión el problema de las continuidades y discontinuidades en la historia del capitalismo mundial. Así como Marx fue el crítico de la estructura de producción y acumulación del siglo XIX y Lenin aportó herramientas teóricas para pensar el imperialismo monopolista de principio del siglo XX, habría que ver hasta que punto Imperio de Negri y Hardt es una mirada renovada para el análisis del capitalismo del siglo XXI o una simple amalgama de ideas y perspectivas inconexas que poco contribuyen a la construcción de una política de tipo transformadora.

\section{Síntesis de Imperio}

¿Cómo describir la tesis básica de Imperio sin repetir lo que tanto se ha dicho? ¿Cómo sintetizar los postulados más importantes planteados por Hardt y Negri evitando caer en lugares comunes? ¿Cómo poder aportar interrogantes nuevos sobre una publicación tan debatida y trabajada en el ambiente académico? Ante estos cuestionamientos lo único que se nos ocurre es renunciar a la faena sin pensarlo dos veces.

Sin embargo, desde nuestra perspectiva, lo que resulta interesante del abordaje de un libro como Imperio no es la novedad del análisis, ni la originalidad de las conclusiones a las que se puede arribar. Más bien, se trataría de conocer las principales afirmaciones vertidas por una obra tan polémica -sobre todo para aquellos que no nos hemos adentrado hasta ahora en el universo teórico que la soporta-con la intención de "descubrir" las claves de su análisis de la realidad política mundial que la han posicionado en el centro de la escena.

A poco de empezar la lectura del libro en cuestión - de hecho en el prefacio- se advierte la tesis central, liminar, sobre la que girará el resto, donde se concentra todo el potencial conflictivo y controversial de Imperio: "Nuestra hipótesis básica consiste en que la soberanía ha adquirido una forma nueva, compuesta por una serie de organismos nacionales y supranacionales unidos por una única lógica de dominio. Esta nueva forma global de soberanía es lo que llamamos imperio" (Hardt-Negri, 2002: 14). Llama la atención la importancia "real", como muchas veces aclaran, que le adjudican a las organizaciones no gubernamentales como las Naciones Unidas.

Según los autores, este nuevo escenario mundial, visible tras el final de la guerra de Vietnam, se avizora a partir del ocaso de la soberanía en su concepción moderna. El "diagnóstico" que elaboran presume que los Estados nacionales han claudicado frente al desarrollo de las nuevas tecnologías de la información y la comunicación que sostienen los procesos de globalización económica.

Con la caída del muro de Berlín y el fin de los gobiernos socialistas, el avance imparable e inexorable del mercado mundial parece haber arrastrado, desde la óptica de Imperio, los viejos mecanismos de regulación estatal de los términos del intercambio económico y cultural.

La pérdida de soberanía del Estado-nación -no sólo fuera de sus fronteras sino también en el interior de su territorio- se anuda a las dificultades que tiene para 
imponer su autoridad en el ámbito económico y la falta de control respecto del tránsito de bienes y personas. Frente a este estado de cosas la conclusión -para ellos- es cantada: "Junto al mercado global y los circuitos globales de producción surgieron un nuevo orden global, una lógica y una estructura de dominio nuevas: en suma, una nueva forma de soberanía. El imperio es el sujeto político que efectivamente regula estos intercambios globales, el poder soberano que gobierna el mundo" (Hardt-Negri, 2002: 13).

Al leer estas afirmaciones de inmediato interrogamos a los autores: ¿Sobre qué elementos basan la existencia del nuevo orden global al que denominan imperio? ¿Qué características novedosas posee? ¿En qué se diferencia del "antiguo" imperialismo? ¿Qué rol juegan dentro de este esquema los países más poderosos como por ejemplo los Estados Unidos?

Sin duda, la aparición de esta estructura de dominación -a la que refieren los autores con el nombre de imperio- guarda una relación estrecha con la declinación del poder de los Estados nacionales mencionado anteriormente, poder que jugó un papel central en la expansión económica de los países europeos durante la era moderna. El desarrollo imperialista característico del siglo XIX, basado en el control de los territorios extranjeros a través de "un sistema de canales y barreras que alternativamente facilitaban y obstruían los flujos de producción y circulación" (Hardt-Negri, 2002: 14), es aniquilado por el avance de este nuevo aparato de dominio. Según la descripción que hacen de este último, a diferencia del imperialismo que demarcaba un centro desde donde ejercía el poder e imponía límites fijos, el imperio es descentrado y desterritorializador. Sus fronteras están abiertas para incorporar a todos los territorios sin distinciones y jerarquías. Desde la perspectiva imperial se va conformando un mapa del mundo sin límites precisos, donde los "colores" que identifican a las distintas naciones se confunden, se mezclan y fusionan, atravesados por redes virtuales e intercambios plurales.

Por lo tanto, hay una clara discrepancia con aquellos intelectuales que creen ver aún hoy en los Estados Unidos al gran digitador de la realidad internacional; aquel que define en última instancia desde su privilegiado lugar en la cúspide del poder, este estado de cosas.

Finalmente, si bien la tarea de resumir una obra tan vasta y ecléctica es un tanto compleja, podríamos sintetizar la tesis general de Imperio en cuatro proposiciones principales:

1- El sistema imperialista como lo hemos conocido tiende a desaparecer y en su reemplazo se erige una estructura de dominio descentralizada y en red denominada imperio.

2- El declinar de la soberanía estatal es el producto del proceso de globalización, impulsado por el desarrollo de las tecnologías de la información y la comunicación, que supone la expansión de la economía capitalista a todas las regiones del planeta.

3- Como consecuencia de ese proceso un nuevo sujeto social, la multitud, irrumpe en escena. Ya no se trata de la clásica noción de lucha de clases sino de la batalla 
entre éstas y el imperio. La multitud se convierte en el sujeto potencialmente transformador de la sociedad capitalista.

A partir de hora nos proponemos desmontar las proposiciones mencionadas a través de un rastreo y reflexión sobre las críticas más consistentes e interesantes vertidas sobre Imperio por los intelectuales, aportando ejemplos que nos ayuden a comprender y revelar las luces y sombras de un libro que pretendió sacudir cierta modorra del pensamiento político con una gran dosis de irreverencia y provocación. En este sentido logró su propósito.

\section{1- La guerra como evidencia}

Una de las objeciones más recurrente a la primera tesis enumerada es la falta de fundamentación empírica que se advierte en la afirmación del fin de la etapa imperialista del capitalismo. "Imperio es un libro extraño. En el momento en que Estados Unidos es la única superpotencia, cuando casi un 50 por ciento de las 500 mayores empresas multinacionales están domiciliadas y son de propiedad estadounidense y cuando Washington está liderando una guerra de intervención contra Afganistán -después de anteriores guerras intervencionistas en los Balcanes, América Central (Panamá), el Caribe (Granada) y guerras por delegación en Colombia (Plan Colombia) - y antes en Angola, Mozambique, Nicaragua, los autores de este libro tan elogiado nos dice que el imperialismo es algo del pasado" (Petras, 2002).

Lo planteado por Petras se vuelve aún más evidente tras la invasión de los Estados Unidos a Irak en 2003. En un mismo sentido apuntan los argumentos de Atilio Boron contra la proposición de una nueva estructura de dominio global que marcaría un corte con el tradicional esquema de poder desplegado por los países occidentales sobre su esfera de influencia y la negación del rol preponderante que juegan hoy los Estados Unidos en el concierto mundial.

Lejos de abrir posibilidades inéditas de resistencia para los Estados periféricos como augura en sus pasajes más optimistas -y de terminar con los "crueles regímenes del poder moderno"- la fase "posmoderna" de la historia parece encaminarse hacia la consolidación de la dominación imperialista encabezada por la hegemonía norteamericana.

Para los intelectuales citados, los entretelones de esta guerra desatada bajo la consigna de aniquilar "el eje del mal" no dejan dudas de su carácter imperialista. Se trató de la decisión unilateral de la superpotencia mundial del norte que invadió territorio extranjero pasando por alto cualquier participación de los llamados "organismos supranacionales". Estas entidades, como las Naciones Unidas, que constituirían el marco legal del imperio, quedaron casi sin razón de ser ante la avasallante imposición de los intereses políticos y económicos norteamericanos en Medio Oriente.

Desde la perspectiva de Hardt y Negri, las formas jurídicas adoptadas por los organismos supranacionales aparecen como uno de los "síntomas" más claros de la conformación de este nuevo orden global -superador de las restricciones del viejo "concierto" internacional- cuyos valores apuntan a la paz y al cese de los 
conflictos. El modelo de autoridad imperial, basado en el reconocimiento de un poder central independiente de los Estados nacionales y desplegado tras el fin de las guerras "interimperialistas", se asemeja entonces al de "una máquina que impone procedimientos de acuerdos continuos" (Hardt-Negri, 2002: 32). En momentos de crisis, cuando el orden imperial se ve amenazado, se arroga el derecho de intervenir de manera excepcional en nombre de principios éticos superiores y de ejercer la fuerza policial necesaria para recuperar el equilibrio perdido.

Resulta difícil sostener, atendiendo a los hechos históricos, que el Imperio legitimó la intervención armada a partir del consenso y los valores éticos en términos de "guerra justa" dado que el propio Consejo de Seguridad de la ONU nunca avaló la invasión que fue calificada de "ilegal". De hecho, la incursión a Irak provocó un cimbronazo en la relación entre las grandes potencias que se dividieron entre aquellas que se opusieron activamente a la invasión -Francia, Bélgica, Alemania, Rusia y China- y quienes la apoyaron, como España, Inglaterra e Italia.

"La idílica idea planteada por Hardt y Negri de los Estados Unidos renunciando a la defensa de sus intereses nacionales y al ejercicio del poder imperialista, y transfiriendo su soberanía a un quimérico imperio, en aras del cual la Casa Blanca responde magnánimamente al clamor internacional en pro de la justicia y el derechos globales quedó sepultada por el aluvión de bombas inteligentes que se descargaron sobre la geografía iraquesa" (Boron, 2004: 14).

Pero más allá del caso concreto de la guerra de Irak que socava sin sutilezas los argumentos de Imperio, para Samir Amin la razón principal por la cual el sistema mundial contemporáneo seguirá siendo imperialista es su propia "naturaleza" polarizante, cuya lógica tiende desde su origen a la constitución de centros dominantes y periferias dominadas y a su reproducción más profunda en cada etapa. "Esta teoría asocia al imperialismo con el proceso de acumulación del capital a escala mundial, hecho que considero como una sola realidad con diferentes dimensiones, de hecho indisociables" (Amin, 2004).

\section{2- La salida estatal a la crisis financiera}

Como mencionábamos al principio, el fin de la etapa imperialista decretada por Imperio y su relevo por un nuevo paradigma de poder va de la mano de la decadencia de las soberanías nacionales y la acentuación de los procesos de globalización en el mundo. En este sentido, el desarrollo abrumador de las tecnologías de la información y la comunicación -además de fomentar la extensión de la economía capitalista a todas las regiones del planeta- ha alentado la visión de un universo interconectado e inmaterial donde no existen límites precisos y es casi imposible para los Estados gobernar o regular los flujos e intercambios de dinero, bienes, tecnología y personas.

A contramano de la segunda tesis apuntada al comienzo, numerosos investigadores sostienen que el carácter global del sistema capitalista no supone necesariamente, como contrapartida, la declinación del Estado nación. Más bien, destacan la profundización de la brecha que separa a las naciones del "primer mundo", que han advertido la necesidad de reforzar la capacidad de sus instrumentos de 
intervención en la economía, de las "tercermundistas", presionadas a acatar los designios de los organismos multilaterales de crédito en materia de políticas públicas.

De hecho, para el sociólogo Eduardo Gruner -en línea con los planteos de Samir Amin o Immanuel Wallerstein- la tan mentada "globalización" lejos de ser una novedad de la era posmoderna, es un producto de la propia lógica del sistema capitalista en su carácter expansivo que se inició hace 500 años con los procesos de colonización. Una afirmación que cobra fuerza si se tiene en cuenta que el trabajo, el resorte fundamental de la producción de plusvalía, está cada vez menos mundializado (Grunner, 2002: 13).

De esta manera, la aparente "libre movilidad" de los distintos factores productivos a través de las fronteras -sostenida por los cultores de la ideología neoliberal-se ve restringida cuando de mano de obra se trata. El papel protagónico que aún detentan las formaciones jurídico-políticas estatales se pone en evidencia en el férreo control que ejercen los países centrales sobre los "flujos mundiales" de esa fuerza de trabajo, a través de la implementación de políticas inmigratorias cada vez más restrictivas. Un párrafo aparte merece el sustrato racista que le reprochan los autores a la soberanía nacional moderna, constitutiva del Otro negativo que daba sustento a la avanzada colonial, negando su persistencia en la actualidad.

De la lectura de Imperio se desprende la idea de que en la nueva estructura de poder esas "prerrogativas reales" de los Estados son cedidas o traspasadas, en ciertos aspectos, a las grandes empresas industriales y financieras, trasnacionales y multinacionales que constituyen "el tejido conectivo fundamental del mundo biopolítico" (Hardt-Negri, 2002: 45).

Al parecer, en el capitalismo global las directivas económicas pasan a ser una facultad de estas empresas que se van a encargar, según Hardt y Negri, de distribuir la fuerza de trabajo en los diversos mercados, asignar funcionalmente los recursos y organizar jerárquicamente los diversos sectores de la producción mundial. Con entusiasmo proclaman: "iel Estado ha sido derrotado y las grandes empresas gobiernan la Tierra!" (Hardt-Negri, 2002: 285).

La debacle financiera que azota los mercados del mundo por estos días, ocupando el centro de la escena mediática con todo tipo de pronósticos apocalípticos, bien podría alentar esta concepción posmoderna de los autores de un sistema de poder que funciona al margen de los Estados nacionales, en el cual lo que prima son los movimientos y flujos internacionales irregulares e incontrolados que fracturan las unidades y oposiciones binarias propias de la soberanía moderna (HardtNegri, 2002: 139).

El principal motivo que justificaría tal comparación es la falta total de regulación demostrada por los gobiernos, en especial el de los Estados Unidos, respecto del accionar de las entidades bancarias y el sistema financiero que han puesto en jaque a la economía mundial. Un nuevo "instrumento", que fue diseñado con el fin de multiplicar las ganancias en la bolsa, permitió expandir el mercado de hipotecas en forma ficticia y ofrecer gran cantidad de créditos, incluso de alto riesgo, es decir, con baja probabilidad de cobro. La situación se complicó aún más cuando 
esas hipotecas fueron metidas adentro de un gran paquete y vendidas en forma de bonos. Obviamente el fin no era garantizar la vivienda digna a los ciudadanos de bajos recursos y pronto, ante el aumento de las tasas de interés y la cesación de pagos de los clientes, la "burbuja" creada por los expertos de Wall Street explotó. En este contexto de crisis generalizada, que recuerda la Gran Depresión de 1929, las recetas del liberalismo más ortodoxo resultan insuficientes hasta para el mismísimo presidente George Bush, quien propuso al Congreso un plan de salvataje por 700 mil millones de dólares con el objetivo evitar, según su diagnóstico, las peores consecuencias de la recesión.

A primera vista la fuerte intervención del Estado en los mercados, destacada como una de las mayores en la historia del país, no sólo choca de lleno con la tesis de Imperio sobre la "derrota" irremediable de dicha institución política y su desaparición futura. Además, implica un cierto reconocimiento de la inoperancia de los postulados esenciales del Consenso de Washington -por parte de uno de sus máximos cultores- a la hora de intentar superar la crisis.

Sin embargo, al analizar con más detenimiento, se observa que la intromisión del gobierno norteamericano en el sistema no tiene nada de excepcional, ya que lo que se busca restablecer y asegurar es el funcionamiento del proceso de acumulación del capital. Esto se evidencia en las condiciones de la primera versión del proyecto de salvataje que exigía al parlamento la aprobación a libro cerrado de una enorme asignación de dinero sobre la cual otra vez no tendrían ningún control y cuyos receptores iban a ser, discrecionalmente, algunos grandes bancos, sin mencionar siquiera a los deudores acuciados por el remate de sus hogares.

A contramano de la metáfora de la "mano libre del mercado" que se cuela en los planteos de Hardt y Negri, Petras destaca la "gestión" de las distintas crisis económicas que a lo largo de la historia reciente han realizado los Estados Unidos con el objetivo de salvar de la bancarrota a importantes inversionistas, apuntalar a compañías insolventes e impedir el quiebre del mercado financiero. "Más que nunca, las empresas multinacionales y la llamada 'economía global' dependen de la constante y masiva intervención de los Estados imperiales en la gestión de la crisis, y en la obtención de beneficios mediante las adquisiciones de empresas locales".

Para Boron, es claro que la defensa de los intereses de estos gigantes empresariales -a los que nomina "leviatanes"-por parte de los países desarrollados no es una actitud inusual tomada ante el inminente colapso. Esto refuerza los argumentos en contra de la tesis de Imperio que afirma la imposibilidad de hablar de economías nacionales en un mundo virtual, desterritorializado y en red: "Su creencia en la desaparición de los productos, empresas e industrias nacionales es absolutamente indefendible a luz de la evidencia cotidiana que demuestra la vitalidad, sobre todo en los países más desarrollados, de tarifas aduaneras, barreras no arancelarias y subsidios especiales por los cuales los gobiernos buscan favorecer de mil maneras a sus productos nacionales, su empresas y sus actividades económicas" (Boron, 2004: 58). 


\section{3- La multitud: de cacerolas y asambleas}

En una visión altamente optimista, los autores de Imperio le confieren a la multitud una gran capacidad potencial de transformación. Sin embargo, al utilizar este término, que adolece de ser demasiado abarcador, no queda muy claro a quién nos referimos: ¿quiénes son parte de la multitud y quiénes no?

Es preciso tener en cuenta que la multitud no implica necesariamente un carácter transformador y ni siquiera progresista. De hecho, puede constituir desde lo político una fuerza más bien reaccionaria. Es por esto que algunos autores, que se inscriben dentro de la corriente del "marxismo posestructuralista", hablan de ambivalencia para explicar este fenómeno a primera vista contradictorio.

El propio Zizek, quien en un primer momento saludó con vehemencia la 11egada de Imperio a las librerías, más tarde llamaría la atención sobre el peligro del despojo del sentido spinoziano de multitud que forzaban los autores: "El slogan de Hardt y Negri -la multitud como sitio de resistencia del Imperio- abre una extensa serie de problemas, siendo el primero de ellos la pérdida de la ambigüedad radical de este término en Spinoza, de quien se lo toma. Cuando Spinoza describe cómo una multitud se conforma a través de la imitatio afecti, los mecanismos que él evoca son completamente neutrales con respecto a sus efectos "buenos" o "malos". Spinoza evita ambas recaídas del enfoque tradicional de la siguiente manera: no subestima el mecanismo de formación de las masas, considerándolo como la fuente de la chusma destructiva irracional, ni lo celebra como el origen de la autosuperación altruista y la solidaridad...Es con respecto a esta neutralidad que la distancia que separa a Negri y Hardt de Spinoza se hace palpable: en Imperio, encontramos una celebración de la multitud como fuerza de la resistencia, mientras que, en Spinoza, el concepto de masa como multitud es fundamentalmente ambiguo: la multitud es la resistencia al Uno impuesto, pero, al mismo tiempo, designa lo que nosotros llamaríamos la turba, una explosión salvaje, irracional de violencia que, a través de la imitatio afecti, se alimenta y se propulsa a sí misma" (Zizek, 2004: 42).

En este sentido, la multitud, desde el punto de vista operativo, desplaza al concepto de clase y de lucha entre ellas. El problema que presenta el término es que evita definir una cuestión básica: contra quién lucha la multitud y en dónde estaría encarnado el imperio. Es decir, elude la identificación del enemigo y la delimitación del escenario en el cual se llevará adelante la resistencia.

Quizás los autores intentan dar respuesta a esto cuando se refieren a los movimientos antiglobalización. Sin embargo, al abarcar diferentes intereses sectoriales, por no decir de clases, desde los granjeros conservadores y grupos ecologistas, hasta los sin tierra de Brasil y diferentes organizaciones de derechos humanos y de inmigrantes, no permite reflexionar sobre la problemáticas "nacionales", ni preguntarse por la cuestión del poder.

Unas preguntas "ingenuas" -como las que hace Zizek- serían: ¿Qué hace la multitud con el poder? ¿Dónde está el poder, por otra parte? ¿O es que acaso se puede "cambiar el mundo sin tomar el poder", como dice John Holloway? Estos interrogantes, obviamente, quedan en suspenso en el discurso de Negri y Hardt. 
Los sucesos de 2001 en Argentina suelen ser tomados como ejemplo de la irrupción y fortaleza de la multitud. La "alianza" entre "caceroleros", "piqueteros" y el funcionamiento de las "asambleas barriales" fueron para muchos la expresión de un fenómeno de nuevo signo que este concepto venía a cubrir y explicar.

Pero podríamos decir que el propio movimiento social generado por la crisis institucional careció de formas positivas de organización sustentables. No sólo la alianza duró poco -las clases medias que en un principio saludaron al movimiento piquetero luego le dieron la espalda- sino que además las asambleas no fueron más que una "ilusión" de restitución de una forma de participación política. Las fuerzas "creativas" de la multitud no se plantearon formas de organización "contraimperio", como imaginaban los autores.

Es más, se podría afirmar que el error está en el propio concepto de multitud, con el que estos autores analizan distintas explosiones del nuevo sujeto social: plaza de Tiananmen, la intifada contra la autoridad israelí, la sublevación en Los Ángeles, el levantamiento de Chiapas, las huelgas que paralizaron Francia y otra en Corea del Sur. Justamente estos ejemplos, como otros de nuevas características, como la explosión de jóvenes en los barrios periféricos de Francia que quemaban autos en el año 2005, demuestran que la multitud no permite analizar la complejidad de las diferencias particulares de cada suceso.

Así como la intifada es la forma de lucha de las masas sojuzgadas palestinas contra el Estado israelí, las quemas de autos son la expresión de los jóvenes emigrantes franceses que responden ante situaciones de exclusión y desocupación. Cada singularidad, en realidad, puede ser mejor pensada a partir del "viejo" concepto de lucha de clases, como concepto central que marca el antagonismo fundamental que determina otros tipos de antagonismos: étnico, racial, nacional, etc. ¿Por qué para Negri y Hardt el concepto de lucha de clase no sirve para explicar estos fenómenos de fines de siglo XX y principio del siglo XXI? Los autores de Imperio no se detienen a explicarlo.

\section{Conclusión}

Una conclusión fácil y tentadora a la que podemos arribar tras leer Imperio y recorrer las críticas que se le han realizado, es que nos encontramos frente a un relato de tipo fantástico, que no tiene nada que ver con las condiciones actuales del capitalismo mundializado. En este sentido, se afirmaría que el sistema capitalista no ha generado nada nuevo y que se trata de más de lo mismo. Sin embargo, quizás lo pertinente sería pensar, sin caer en dicotomías polarizantes, la dinámica del sistema bajo el aspecto de la dialéctica de lo nuevo y lo viejo. Aquello que es novedoso, pero suele tratarse como "más de lo mismo" o a la inversa, no comprender que aquello que se presenta como "novedoso" no es más que la expresión de viejas cuestiones.

No se trata de negar algunos cambios fundamentales que se han producido en el capitalismo. El propio concepto lleva en su interior esa característica: un modo de producción dinámico, que está siempre transformándose, que es su contradicción fundamental la que hace que esté en constante "revolución". Esa dinámica 
se expresa en las formas "nuevas" que adquiere el trabajo, en las características particulares de la lucha política, en situaciones que hablan de diferentes posicionamientos de los sujetos sociales.

No se puede negar, por ejemplo, que las revoluciones en el marco de las tecnologías de las comunicaciones han tenido un fuerte impacto tanto en el terreno de lo "ideológico", como en el marco de lo político o de las formas, en realidad, de hacer política. Esto no significa ningún fin, como ha sostenido cierto posmodernismo, sino la aparición de un nuevo escenario que de alguna manera ha impactado sobre el propio concepto de clase social.

Hoy, tal vez, no es posible asociar a la clase obrera sólo con la figura del overol del clásico trabajador industrial, pero tampoco decir que no existe la clase obrera. De hecho, la clase se ha "extendido" hasta abarcar a los trabajadores de otros sectores, como el de servicios, y a los propios desocupados, que -como Marx ya decía- representan la mano de obra de recambio.

De todos modos, habría algo importante para rescatar del libro Imperio: es que se trata de un esfuerzo de restituir la idea de totalidad. Esta obra de Negri y Hardt aparece en un momento en el que determinadas cosmovisiones estaban ya dadas por muertas por el posmodernismo que sostenía el fin de los grandes relatos. La sola idea de pensar la posibilidad de un mundo diferente y alternativo al sistema capitalista, independientemente del modo en que se lo haga, es una bocanada de aire fresco que restituyó el ánimo polemista en el marco de las ciencias sociales. De algún modo se apartaron del modelo hegemónico "posmoderno" del fragmento y lo micro, para pensar nuevamente la historia, el sujeto, la transformación social, y construir un "gran relato". Una teoría "fuerte" a contrapelo de las teorías

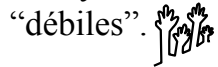

\section{Bibliografía}

S. AMIN (2004), "Geopolítica del imperialismo contemporáneo", en A. BORON (Comp.), Nueva hegemonia mundial. Alternativas de cambio y movimientos sociales, Buenos Aires, CLACSO

A. BORON (2004), Imperio \& Imperialismo: una lectura crítica de Micheal Hardt y Antonio Negri, 5ta. edición, Buenos Aires, CLACSO.

E. GRUNER (2002), El fin de las pequeñas historias, Buenos Aires, Paidós.

N. KOHAN, "El imperio de Hardt \& Negri y el regreso del marxismo eurocéntrico", http://www. cuestiones.ws/semanal/030503/sem-may03-03-kohan.htm Fecha de acceso: 10/09/2008.

A. NEGRI, M. HARDT (2002), Imperio, Buenos Aires, Paidós.

A. NEGRI, M. HARDT (2002), "La multitud contra el imperio", en Revista del Osal, No 7, Buenos Aires, CLACSO - Observatorio Social de América Latina.

J. PETRAS (2002), "Imperialismo versus Imperio", en Revista Laberinto, № 8. http://laberinto.uma. es/index.php?option=com content\&task=view\&id=175\&Itemid=34. Fecha de acceso: 5/08/2008.

A. RUSH (2003), "La teoría posmoderna del Imperio (Hardt \& Negri) y sus críticos", en A. BORON (comp.), La Filosofía Política Contemporánea, Buenos Aires, CLACSO.

http://bibliotecavirtual.clacso.org.ar/ar/libros/teoria3/rush.pdf Fecha de acceso: 13/08/2008. S. ZIZEK, (2004), La revolución blanda, Buenos Aires, Atuel. 